\title{
Setting up a men's clinic has never been an easy task. I have done it, and here is my story
}

\author{
Mohd Ismail Bin Mohd Tambi \\ Asian Journal of Andrology (2011) 13,607-608; doi:10.1038/aja.2010.128; published online 14 March 2011
}

Dear Editor,

Almost a quarter of a century ago, having completed a diploma in reproductive medicine, I was sent to the Monash Medical Research Centreat Prince Henry's Hospital in St Kilda, Melbourne, Australia, on a fellowship in clinical andrology and semenology. Professor H. W. Gordon Baker and the present governor of Victoria, Professor David de Kretser, were my mentors in andrology.

Upon my return, I expanded the male fertility and sexuality component in the existing services provided by the Specialist Reproductive Research section of the National Population and Family Development Board, where I had been placed. My initial work was to ensure that the men's clinic had sufficient infrastructure support, including the medical instruments that are usually required in standard general practice as well as medical instruments specific to a male clinic such as an instrument to measure testicular volume, a Prader's orchidometer, a Varicoscreen (a heat-sensitive device to detect varicosele), a good light source, a magnifying lens to examine the male external genitalia, and models of the male genitalia and reproductive system for the purpose of counselling men and their partners. Once these were available, more equipment and services were added from year to year according to demand.

Eliciting male participation in reproductive health programmes has been rather challenging in my country. More often than not, when a couple has had difficulty conceiving, the man will decline investigation for fear that he may be the cause of the 'infertility'. When I began working in the clinic, men did not realize that it was the profile of their sperm - the concentration, motility and morphology - that was important in achieving pregnancy, not the frequency of sexual intercourse. A great deal of education was required to get the message across.

The clinic setting is not the ideal situation for collecting semen specimens when clients must use the bathroom and do not have the assistance of sexually explicit materials. The solution was a special room that had a TV and VCD player and sexually explicit materials and videos. Couples who wanted instead to collect specimens through sexual intercourse, on religious grounds, were given silicon condoms or semen-collection condoms. These condoms, unlike latex condoms, are nontoxic to sperm.

In most cases, the cause of the male subfertility is unknown; this status is now called idiopathic infertility. Its prevalence can be as high as $70 \%$ and the treatment regimens are mostly empirical.
Male fertility treatment has become more advance to enable men to sire a child. In addition, fertility methods designed for women such as in vitro fertilization and assisted reproductive technology are accepted options for couples in which the man has severe fertility problems.

Men with sexual dysfunction usually came to the clinic because of subfertility, and only in the course of the investigation did it become clear that the problem was a sexual one. Most of our male clients with fertility problems learned about the clinic through word of mouth. The local media provided most of the publicity educating men about their ailments and other health issues. Public health forums on men's disorders were conducted by our centre from time to time until the mid-1990s, when local and electronic media highlighted the male miracle pill, Viagra, in the media frenzy that led men consider modern treatments for their ailment. Prior to the accidental discovery of Viagra, male erectile dysfunction (ED), known as male impotence at that time, was treated with testosterone if the condition was not attributed to the mind. Managing male sexuality problems involved getting the men to come forward for treatment, and this was a challenge because men associate erectile function with their manliness and the ED is a clear sign of their fading virility. They often prefer to suffer in silence than to take action. They tend to take action only when their spouses pressure them, and, before the marketing of Viagra and similar drugs, they might seek folklore treatments and medicines. In my practice, men with ED were encouraged to come to the clinic with their spouse. They were both counselled on ED, and a series of evaluations were done before the men were given a briefing on the available treatments. At the time, the main option was a vacuum erection-aid device; the only other choice was intracavernous injection with prostatin-E. When the first PDE-5 inhibitor, sildenafil citrate, became available, this drug became the most popular choice. As more PDE-5 inhibitors came onto the market, oral therapy was confirmed as the mainstay treatment of ED.

The male clinic, which originally addressed sexual matters affecting married couples has over time gained the confidence of single men through indirect publicity and word of mouth. Premature or rapid ejaculation has never been a problem as long as the man can maintain his erection even after ejaculation, until his capacity declines. The larger problem, then, is persuading men suffering from delayed or retarded ejaculation to seek a solution. Treatment for this issue ranges from counselling to pharmacotherapy, and the successes that have 
been achieved have encouraged men, with the support of their partners, to seek medical assistance.

Men with sexually transmitted infections who were usually seen by the sexually transmitted disease (STD) physicians also visited in the male clinic because the mode of infection was no longer limited to prostitution or sexual promiscuity and infidelity had become common. In addition to fertility and sexuality management, healthy aging has become an emerging need, as more baby boomers live longer than their fathers did. Aesthetic and preventive medicine have emerged to add support to existing health care services. The value of the male clinic became clear when men suddenly realized that they have similar, health needs as their female partners. As men are the principal wage earners, they have more money and power and can demand more health services and innovations to maintain and enhance their lifestyles. 